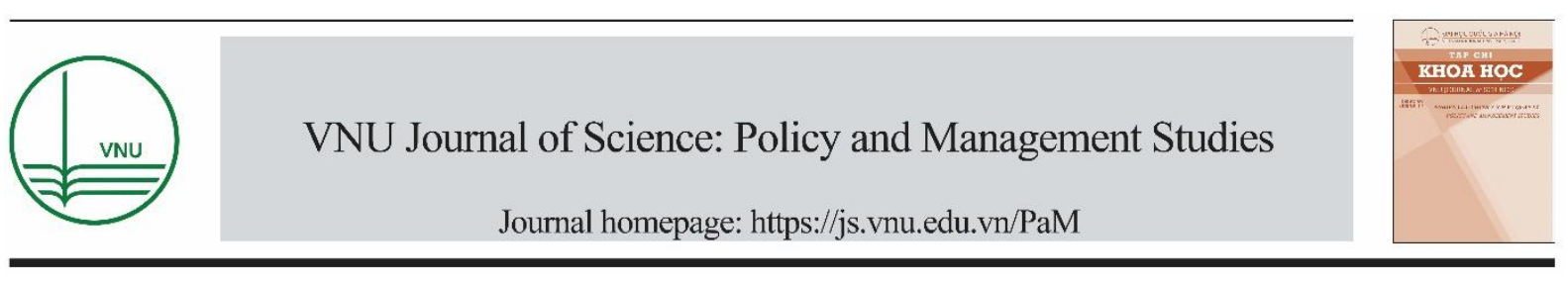
Review Article

\title{
Quality Human Resources in Lam Dong and the Issues Posed
}

\author{
Vu Thi Thuy Dung* \\ Da Lat University, 1 Phu Dong Thien Vuong, Ward 8, Lam Dong, Vietnam
}

Received 17 December 2019

Revised 10 March 2020; Accepted 15 March 2020

\begin{abstract}
Lam Dong is evaluated as a potential province in socio-economic development in the Central Highlands for many years. The development speed of Lam Dong contributes significantly to the development speed of the Central Highlands and the whole country. Contributing to that growth, we must mention Lam Dong's strategy of investing in the quality of human resources. More specifically, the input of high quality human resources based on local strengths is the fast, strong and sustainable direction of Lam Dong in recent years.

This paper focuses on analyzing and evaluating the quality of human resources in Lam Dong in three aspects considered to be "three specialties" of Lam Dong which are human resources in the field of high-tech agriculture and human resources. in the field of tourism services and human resources for ethnic minorities. Since then, the article proposes solutions directions in the strategy for developing human resources, especially high-quality human resources of Lam Dong in the future.
\end{abstract}

Keywords: Human resources, quality of human resources, Lam Dong.

\footnotetext{
${ }^{*}$ Corresponding author.

E-mail address: dungvtt@dlu.edu.vn
}

https://doi.org/10.25073/2588-1116/vnupam.4214 


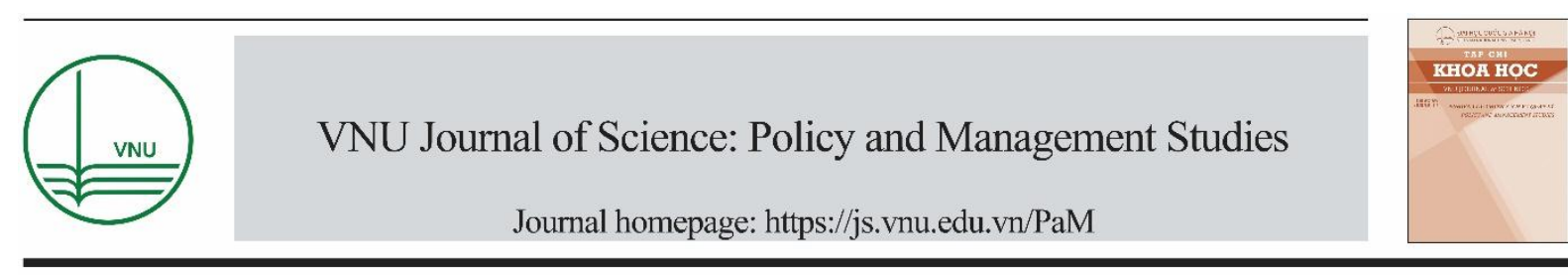

\title{
Chất lượng nguồn nhân lực ở Lâm Đồng và những vấn đề đặt ra hiện nay
}

\author{
Vũ Thị Thùy Dung* \\ Truờng Đại học Đà Lạt, 1 Phù Đổng Thiên Vuơng, Phưòng 8, Lâm Đồng, Việt Nam \\ Nhận ngày 17 tháng 12 năm 2019 \\ Chỉnh sửa ngày 10 tháng 3 năm 2020; Chấp nhận đăng ngày 15 tháng 3 năm 2020
}

\begin{abstract}
Tóm tắt: Lâm Đồng được đánh giá là một tỉnh giàu tiềm năng trong phát triển kinh tế, văn hóa xã hội ở Tây Nguyên nhiều năm qua. Tốc độ phát triển của Lâm Đồng đóng góp không nhỏ vào tốc độ phát triển của Tây Nguyên và của cả nước. Góp phần vào tốc độ tăng trưởng đó, có thể nói do Lâm Đồng đã sớm đầu tư cho chiến lược phát triển nguồn nhân lực chất lượng cao và coi đó là hướng đi nhanh, mạnh và bền vững của Tỉnh trong những năm gần đây.

Bài viết này tập trung phân tích, đánh giá chất lượng nguồn nhân lực ở Lâm Đồng ở ba khía cạnh được cho là "ba đặc sản" (ba lợi thế so sánh) của Lâm Đồng đó là nguồn nhân lực trong lĩnh vực nông nghiệp công nghệ cao, nguồn nhân lực trong lĩnh vực dịch vụ du lịch và nguồn nhân lực đồng bào dân tộc thiểu số. Từ đó, bài viết đề xuất các định hướng giải pháp trong chiến lược phát triển nguồn nhân lực, đặc biệt nguồn nhân lực chất lượng cao của Lâm Đồng trong tương lai.
\end{abstract}

Tù khóa: Nguồn nhân lực, chất lượng nguồn nhân lực, Lâm Đồng.

\section{1. Đặt vấn đề}

Trong xu thế toàn thế giới bước vào cuộc cách mạng công nghiệp 4.0, tập trung chủ yếu vào sản xuất thông minh, nguồn nhân lực chất lượng cao ngày càng thể hiện vai trò quyết định trong phát triển kinh tế - xã hội của đất nước. Lâm Đồng trong nhiều năm qua, được đánh giá là một trong những tỉnh có tốc độ phát triển cao so với bình quân của cả nước và nhiều tỉnh thành khác (xấp xỉ 8\%). Góp phần vào tốc độ

\footnotetext{
*Tác giả liên hệ.

Địa chi email: dungvtt@dlu.edu.vn
}

https://doi.org/10.25073/2588-1116/vnupam.4214 tăng trưởng đó, phải nói đến vai trò của chất lượng nguồn nhân lực của địa phương. Đội ngũ nhân lực của tỉnh đến nay đã có bước phát triển vượt bậc không chỉ về số lượng mà cả về chất lượng và là một trong những nhân tố mang tính quyết định cho sự phát triển kinh tế - xã hội của tỉnh như hiện nay. Bài viết này xem xét một số bước tiến mới trong chất lượng nguồn nhân lực của Lâm Đồng ở các khía cạnh: nguồn nhân lực trong phát triển dịch vụ du lịch, nguồn nhân lực trong phát triển nông nghiệp công nghệ cao và

nguồn nhân lực dân tộc thiểu số. Đồng thời chỉ ra những tồn tại, hạn chế cần đặt ra đối với việc 
phát triển nguồn nhân lực, đặc biệt nguồn nhân lực chất lượng ở Lâm Đồng hiện nay.

\section{Thực trạng về chất lượng nguồn nhân lực ở Lâm Đồng}

2.1. Những lợi thế về nguồn nhân lực trong thị truờng lao động của Lâm Đồng

Có thể nói, Lâm Đồng là một tỉnh còn non trẻ so với nhiều tỉnh thành khác trong cả nước. Tính trẻ của Lâm Đồng không chỉ bởi lịch sử thành lập (31/10/1920) mà còn bởi thành phần dân cư của thành phố. Dân số hiện nay của thành phố là 1.298 .000 người, trong đó 50,38 là nam giới và 49,62\% là nữ giới, $39,29 \%$ dân số sống ở thành thị và $60,71 \%$ là ở nông thôn. Nếu tính riêng lực lượng lao động từ 15 tuổi trở lên, Lâm Đồng có 767.938 người, trong đó lực lượng lao động nam chiếm $52,74 \%$ và lực lượng lao động nữ là 47,26\%.

Nếu tính riêng về chỉ số lao động đang làm việc đã qua đào tạo, thì so với năm 2010 , tỉ lệ này tăng lên $5.2 \%$ (11.7\% năm 2010 lên đến $16.9 \%$ năm 2017), đáng chú ý, tỷ lệ này tăng đều trong 10 năm.

Bảng 1. Tỷ lệ lao động từ 15 tuổi trở lên đang làm việc trong nền kinh tế đã qua đào tạo phân theo giới tính và khu vực ở Lâm Đồng [1]. Đ/v: \%

\begin{tabular}{llllll}
\hline & & \multicolumn{2}{l}{$\begin{array}{l}\text { Phân theo } \\
\text { giới tính }\end{array}$} & \multicolumn{2}{l}{$\begin{array}{l}\text { Phân theo thành thị, } \\
\text { nông thôn }\end{array}$} \\
\cline { 3 - 6 } Năm & \multirow{2}{*}{$\begin{array}{l}\text { Tổng } \\
\text { số }\end{array}$} & Nam & Nữ & Thành thị & Nông thôn \\
\cline { 3 - 6 } 2010 & 11,7 & 12,5 & 11,2 & 21,2 & 6,8 \\
2011 & 12,9 & 13,7 & 12,1 & 22,6 & 7,1 \\
2012 & 13,8 & 14,3 & 13,2 & 22,1 & 9,9 \\
2013 & 16,3 & 17,6 & 14,9 & 21,8 & 12,9 \\
2014 & 14,9 & 15,6 & 14,3 & 22,7 & 9,5 \\
2015 & 15,3 & 16,7 & 13,8 & 24,1 & 10,1 \\
2016 & 16,1 & 17,5 & 14,6 & 24,9 & 10,9 \\
2017 & 16,9 & 17,9 & 15,8 & 25,2 & 11,3 \\
\hline
\end{tabular}

Từ bảng số liệu 1 cho thấy, tỷ lệ lao động ở Lâm Đồng từ 15 tuổi trở nên đang làm việc đã qua đào tạo tăng đáng kể trong 7 năm qua. Tỷ lệ này có sự khác nhau giữa khu vực thành thị và nông thôn, giữa nam và nữ. Cụ thể, ở khu vực thành thị, tỷ lệ lao động đã qua đào tạo cao hơn gấp đôi (có năm gấp ba) so với khu vực nông thôn. Tỷ lệ lao động nam đã qua đào tạo cao hơn so với lao động nữ. Trong số 5 tỉnh Tây Nguyên, Lâm Đồng là địa phương có trình độ học vấn cao nhất [2].

\subsubsection{Nguồn nhân lực trong ngành dịch vu du lich}

Theo Sở Văn hóa, Thể thao và Du lịch Lâm Đồng [3] - toàn tỉnh chiếm trên $60 \%$ lượng khách và $90 \%$ tổng nguồn thu từ du lịch của cả
Tây Nguyên. Thu nhập xã hội từ du lịch đạt khoảng 30.000 tỷ đồng, tạo việc làm cho hơn 10 nghìn lao động trực tiếp trong ngành và trên 25 nghìn lao động gián tiếp ngoài xã hội có liên quan đến hoạt động du lịch.

Số lao động trực tiếp phục vụ ngành du lịch trên địa bàn toàn tỉnh hiện có khoảng 11.200 lao động. Trong đó lĩnh vực lưu trú là 7.600 người; Lĩnh vực lữ hành, hướng dẫn và vận chuyển khách là 1.350 người; Lĩnh vực khu, điểm du lịch là 2.220 người; Cơ quan quản lý về du lịch là 30 người. Trong đó có trên $80 \%$ đội ngũ cán bộ quản lý nhà nước từ tỉnh đến cơ sở được đào tạo chuyên sâu về du lịch, $77 \%$ số lao động trực tiếp đã được đào tạo, bồi dưỡng về nghiệp vụ chuyên môn và ngoại ngữ, $90 \%$ cơ sở đào tạo du lịch [3] xây dựng chương trình 
giảng dạy đáp ứng được yêu cầu thực tiễn. Theo đánh giá của ngành du lịch tỉnh, nhìn chung, hệ thống các trường đào tạo về du lịch tại Đà Lạt Lâm Đồng đã cơ bản đáp ứng khả năng nhu cầu đào tạo, bồi dưỡng cho nguồn nhân lực du lịch. Thậm chí nhiều trường còn cung cấp nguồn nhân lực và tham gia đào tạo về du lịch cho nhiều địa phương khác trong cả nước.

\subsubsection{Nguồn nhân lực trong ngành nông nghiệp công nghẹ cao}

Ở Lâm Đồng, sản xuất nông nghiệp ứng dụng công nghệ cao (NNCNC) là một trong các khâu đột phá mà tỉnh tiếp tục phát triển cả chiều rộng lẫn chiều sâu với mục tiêu rút ngắn khoảng cách tụt hậu, thúc đẩy tăng trưởng kinh tế, phát triển xã hội. Trong việc phát triển $\mathrm{NNCNC}$ thì vấn đề phát triển nguồn nhân lực là một trong những yếu tố quyết định, đó cũng là định hướng của tỉnh về phát triển nhanh nguồn nhân lực, nhất là nguồn nhân lực chất lượng cao. Từ năm 2004, Lâm Đồng đã bắt đầu tiến hành xây dựng nền NNCNC. Đến nay, qua 8 năm, NNCNC đã phát triển mạnh mẽ, góp phần quan trọng vào sự phát triển nông nghiệp của địa phương. Hiện tại, toàn tỉnh có gần 27.000 ha canh tác ứng dụng $\mathrm{CNC}$, chiếm khoảng $8,1 \%$ tổng diện tích gieo trồng hàng năm, trong đó, có trên 10.000 ha có doanh thu từ 200 triệu đến 2 tỷ đồng/ha/năm. Do đó, Lâm Đồng là địa phương được Trung ương đánh giá đứng đầu cả nước về sản xuất NNCNC [4]. Hiện toàn quốc có 4 doanh nghiệp được Bộ NN \& PTNT công nhận doanh nghiệp ứng dụng $\mathrm{CNC}$ thì Lâm Đồng chiếm tới 3 doanh nghiệp (Công ty cổ phần CNSH Rừng hoa Đà Lạt, Công ty Dalat Hasfarm và Công ty TNHH Đà Lạt GAP). Đồng thời, Lâm Đồng còn là địa phương duy nhất trong cả nước xuất khẩu cây giống sang châu Âu có quy mô với 10,5 triệu cây/năm [4]. Lâm Đồng được biết đến và cũng là lợi thế cạnh tranh của tỉnh với nhiều đặc sản về nông nghiệp như trà Blao, cà phê Di Linh, rau và hoa Đà Lạt, lúa gạo Cát Tiên, rượu cần Langbian, nấm Đơn Dương, chuối La Ba,... Bên cạnh đó, đã có nhiều sản phẩm mới có triển vọng xuất hiện từ trong sản xuất nông nghiệp công nghệ cao như cá nước lạnh Đa Nhim, cá lăng Cát Tiên, sâm Đà Lạt, sâm Ngọc Linh, chè dược liệu Thiên Kim, diệp hạ châu Cát Tiên, cam đường không hạt, chè dây Đam Rông.

Lâm Đồng là tỉnh đầu tiên đào tạo nguồn nhân lực $\mathrm{CNC}$ với hàng ngàn người nông dân và doanh nghiệp từ năm 2008, với hình thức mời chuyên gia tập huấn kỹ thuật, tiếp cận sản xuất $\mathrm{CNC}$, tiếp cận thị trường, cạnh tranh quốc tế. Các doanh nghiệp và hộ nông dân hưởng ứng tích cực, mạnh dạn bỏ vốn đầu tư sản xuất. Từ chỗ chỉ vài chục ha ở các doanh nghiệp FDI và chỉ tập trung ở Đà Lạt thì nay sản xuất NNCNC đã mở rộng tới các huyện lân cận như Đức Trọng, Đơn Dương, Lạc Dương... Cũng thông qua chương trình nông nghiệp công nghệ cao, Lâm Đồng đã tạo được cơ hội hợp tác quốc tế trong đào tạo nâng cao chất lượng nguồn nhân lực cho trên 2.000 lượt người về kiến thức sản xuất nông nghiệp công nghệ cao; triển khai được nhiều mô hình sản xuất nông sản có chứng nhận theo tiêu chuẩn quốc tế và tiêu chuẩn quốc gia như ORGANIK, HACCP, GlobalGAP, VietGAP.

Xét về qui mô và cơ cấu nguồn nhân lực nông nghiệp công nghệ cao ở Lâm Đồng hiện nay đã phát triển tương đối đồng bộ ở nhiều loại nông sản và có ở hầu hết các công đoạn của quá trình sản xuất nông nghiệp, bao gồm từ nhân lực trong lĩnh vực nghiên cứu và ứng dụng tiến bộ sinh học (giống, kĩ thuật biến đồi gene,...) đến nhân lực trong ứng dụng các kĩ thuật canh tác tiên tiến ( kĩ thuật tưới, tiêu, kĩ thuật bón phân, màng che, điều hoà độ ẩm, ánh sáng...) và nhân lực trong việc ứng dụng các công nghệ "mềm" (cơ chế tổ chức, quản lí tiên tiến, các hoạt động bảo hộ sở hữu trí tuệ,... ).

Bên cạnh đó, nhiều mô hình phát triển nông nghiệp công nghệ cao ở Lâm Đồng trong thời gian qua cũng phát triển rầm rộ. Có thể hình dung ra ba mô hình phát triển nhân lực nông nghiệp công nghệ cao ở Lâm Đồng [5] trong thời gian qua: đó là mô hình dựa trên sự tác động của Nhà nước; mô hình từ sự chủ động phát triển của các doanh nghiệp và mô hình 
phát triển tự phát của các cá nhân hoặc hộ gia đình đều đã có tỏ rõ lợi thế cạnh tranh cho sự phát triển của ngành nông nghiệp công nghệ cao nói riêng và cho sự phát triển nhân lực nông nghiệp công nghệ cao ở Lâm Đồng nói chung.

\subsubsection{Nguồn nhân lục đồng bào dân tộc thiểu số}

Lâm Đồng là tỉnh miền núi nam Tây Nguyên, có hơn 1,28 triệu người, với 43 dân tộc sinh sống, trong đó dân tộc thiểu số (DTTS) chiếm hơn $24 \%$ dân số toàn tỉnh. Trong đó dân tộc thiểu số gốc Tây Nguyên có 207.718 người chiếm $16,7 \%$, những sắc tộc có đông dân số là K'ho (152.855 người), Chu ru (19.551 người), Mạ (33.442 người) [6].

Lâm Đồng có 133/147 xã, phường, thị trấn có đồng bào dân tộc thiểu số sinh sống. Trong đó tỷ lệ đồng bào dân tộc thiểu số: từ $70 \%$ trở lên có 25 xã; từ $50 \%$ đến dưới $70 \%$ có 15 xã; từ 40\% - 49\%: 8 xã; từ $20 \%$ - 39\%: 22 xã; dưới 19\%: 15 xã và các xã còn lại có tỷ lệ dân tộc thiểu số không lớn là 63 xã [7]. Với mục tiêu xây dựng Lâm Đồng đến năm 2020 trở thành tỉnh phát triển của vùng Tây Nguyên, Lâm Đồng luôn coi đào tạo, phát triển và nâng cao chất lượng nguồn nhân lực là nhiệm vụ thường xuyên, trọng tâm và có tính chiến lược lâu dài. Toàn tỉnh đào tạo nghề cho gần 1.300 lao động là đồng bào DTTS, trong đó đào tạo trình độ cao đẳng 600 sinh viên, trình độ trung cấp 250 học sinh, đào tạo thường xuyên gần 500 lao động; xuất khẩu lao động cho 71 người là đồng bào DTTS [7]. Đây được coi là dấu hiệu đáng mừng cho chất lượng nguồn nhân lực đồng bào dân tộc thiểu số Lâm Đồng nói riêng và vai trò đóng góp trong thị trường lao động nói chung của người đồng bào dân tộc thiểu số ở Lâm Đồng.

\subsection{Nhũng hạn chế về nguồn nhân lục ở Lâm Đồng}

Bên cạnh những mặt mạnh, lợi thế đã đề cập ở phần trên, mặc dù là tỉnh có nhiều tiềm năng để phát triển, nhưng Lâm Đồng chưa khai thác được nguồn nhân lực đúng mức và có hiệu quả. Một trong những nguyên nhân quan trọng là thiếu nguồn nhân lực phù hợp và có chất lượng trong các lĩnh vực kinh tế trọng điểm [8].

\subsubsection{Hạn chế về chất lương nguồn nhân lực làm du lịch}

Tuy nhiên, việc phát triển du lịch chất lượng cao theo yêu cầu mới đặt ra: phát triển "du lịch thông minh", "du lịch an toàn, bền vững", .. đối với Lâm Đồng trong những năm qua còn nhiều bất cập. Vẫn còn nhiều hạn chế, yếu kém, bất cập trong công tác quản lý, điều hành của các cơ quan nhà nước đối với du lịch; tư duy kinh doanh chộp giật theo kiểu "ăn xổi ở thi” của một số doanh nghiệp; hiện tượng "chặt chém", bắt chẹt, thậm chí hành hung khách du lịch vẫn còn; thực trạng "cò" trong hoạt động du lịch vẫn tồn tại. Đặc biệt là thiếu sự an toàn tính mang cho du khách khi tham gia các hoạt động du lịch thể thao mạo hiểm, chưa phát huy cho được phong cách "Thanh lịch - Hiền hòa Mến khách" trong hoạt động du lịch, kinh doanh dịch vụ,... Tất cả những tồn tại và hạn chế này có thể được tìm thấy ở nhân tố con người - nguồn nhân lực du lịch chưa thực sự đảm bảo. Một trong những nguyên nhân nhận thấy rõ nhất chính là việc quản trị chiến lược trong phát triển du lịch của tỉnh, trong đó quản trị chiến lược nhân sự trong làm du lịch. Mặc dù trên $70 \%$ lao động trực tiếp ngành du lịch được đào tạo chuyên môn, nghiệp vụ. Nhưng trong thực tiễn, việc cạnh tranh doanh thu và tồn tại thị trường khiến nhiều đối tượng làm du lịch lơ là các nguyên tắc trong hành nghề, trong phát triển cùng với khâu quản lý chưa chặt chẽ và nghiêm túc khiến nhiều sai phạm của ngành cũng như hình ảnh về du lịch của tỉnh bị ảnh hưởng. Cụ thể, riêng trong năm 2018, trong số 259 lượt cơ sở kiểm tra đã phát hiện 229 vụ vi phạm gồm 93 cá nhân, 136 tổ chức. Hoạt động phối kết hợp trong quản lý nhà nước liền quan chưa đạt kết quả cao: Thông tin, dữ liệu, số liệu thông báo lưu trú từ các cơ sở kinh doanh lưu trú là nguồn đầu vào quan trọng cho nhiều hoạt động quản lý Nhà nước của các cơ quan hữu quan như ngành Công an, cơ quan quản lý Du lịch, cơ quan quản lý Thuế,... Tuy nhiên, thực 
tế hiện nay các dữ liệu này chưa thống nhất mà được lấy từ nhiều nguồn khác nhau nên tính cập nhật, tính đầy đủ và độ tin cậy chưa được khẳng định. Do đó, việc thực hiện các nghiệp vụ quản lý chuyên trách của các cơ quan quản lý chỉ thực hiện ở mức độ riêng lẻ mà chưa đạt được sự đồng bộ cao trong phối hợp quản lý lưu trú nói riêng và quản lý kinh tế - xã hội nói chung (thanh tra, kiểm tra, thực hiện các chế tài quản lý, thu thập báo cáo số liệu,...). Các hoạt động quản lý chưa mang tính đồng bộ như vậy, thực chất là do chất lượng đội ngũ hạn chế, cũng sẽ là nguyên nhân tạo ra nhiều điều chưa thuận lợi cho các doanh nghiệp, dễ dẫn đến các yếu tố sai phạm có tính chất tiêu cực ảnh hưởng đến quản lý và phát triển chung.

Nguyên nhân tiếp theo, nhiều doanh nghiệp sử dụng lao động chưa thực sự quan tâm đến việc tuyển dụng và sử dụng lao động đã qua đào tạo. Đồng thời còn có tình trạng "nhà nhà làm du lịch, người người làm du lịch" nhưng không qua đào tạo, không được hướng dẫn bài bản, chuyên nghiệp nên ảnh hưởng lớn tới chất lượng dịch vụ du lịch của tỉnh.

\subsubsection{Hạn chế trong phát triển nhân lực nông nghiệp công nghệ cao}

Vấn đề phát triển nguồn nhân lực phục vụ cho nông nghiệp ứng dụng công nghệ cao còn nhiều hạn chế, còn thiếu cả về số lượng, cơ cấu và chất lượng. Theo thống kê của ngành chức năng [4], hiện nay, toàn tỉnh cần phải có thêm 2.000 cán bộ khoa học kỹ thuật ngành công nghệ sinh học, trong đó, có khoảng 150 cán bộ đầu ngành, và dự kiến đến năm 2020 mới có đủ cán bộ đáp ứng nhu cầu nghiên cứu phát triển công nghệ, giảng dạy, quản lý và sản xuất kinh doanh về công nghệ sinh học. Đặc biệt là nhân sự về các lĩnh vực công nghệ sinh học, công nghệ nano, công nghệ thông tin quản trị tài chính thông minh, công nghệ đồng bộ năng lượng tái tạo, công nghệ rô bốt. Nếu có nguồn nhân lực ở các mảng này, chắc chắn sẽ đem lại lợi thế cạnh tranh, lợi thế so sánh rất lớn cho Lâm Đồng không chỉ trong nước mà còn cả thị trường quốc tế.
Nguyên nhân tiếp theo được nhắc đến đó là các nghề đào tạo trong các trường đại học, cao đẳng của tỉnh liên quan đến nông nghiệp công nghệ cao thu hút không nhiều số lượng sinh viên học, mặc dù khi ra trường, các em có việc làm đạt tỷ lệ cao nhất.

Một nhân tố cần phải chú ý là các nông dân, nông hộ trực tiếp tham gia vào sản xuất nông sản. Do đó, đào tạo nguồn nhân lực NNCNC cần gắn với thị trường lao động và đào tạo nghề. Và đào tạo nghề cho người dân là một hướng đi cần thiết, vì người nông dân vừa là người lao động nhưng cũng là những chuyên gia trên đồng ruộng. Tuy nhiên, để phát triển nguồn nhân lực NNCNC thì không thể thiếu những cơ chế, chính sách từ nguồn lực Nhà nước nhằm tạo nền tảng mở đường, tạo động lực, từ đó, phát huy được nguồn lực con người, nội lực của người nông dân và tiềm năng, lợi thế so sánh trong phát triển nông nghiệp của địa phương.

Và cũng liên quan đến ba mô hình như phần thành tựu, cần có câu trả lời cho câu hỏi vậy trong 3 mô hình hình thành và phát triển nhân lực nông nghiệp công nghệ cao ở Lâm Đồng trong thời gian qua thì mô hình nào là hiệu quả và bền vững nhất? Vai trò của các cơ quan quản lí nhà nước và các đơn vị nghiên cứu - chuyển giao công nghệ, các nhà khoa học nên như thế nào? Đâu là định hướng cơ bản cho việc phát triển nguồn nhân lực nông nghiệp công nghệ cao ở tỉnh Lâm Đồng trong thời gian tới? Phải chăng, trọng tâm của việc phát triển nhân lực nông nghiệp công nghệ cao chính là áp dụng mô hình đâu tư cho các doanh nghiệp nông nghiệp ứng dụng công nghệ cao có đủ qui mô (bao gồm cả các tổ hợp, các hợp tác xã) và vùng sản xuất nông nghiệp ứng dụng công nghệ cao.

Vấn đề thứ ba là, thực tiễn phát triển nhân lực nông nghiệp công nghệ cao ở Lâm Đồng trong thời gian qua còn có khá nhiều yếu tố tác động đến như vấn đề vốn, bảo hộ quyền sở hữu trí tuệ, phát triển các công nghệ phụ trợ (như bảo vệ cây trồng, vật nuôi...) và vấn đề thị trường... Trong các vấn đề đó, có một vấn đề khá quan trọng: đó là mô hình tổ chức quản lý và sản xuất. Việc tổ chức quản lý và sản xuất 
theo mô hình trang trại gia đình (nhà vườn) khá phổ biến hiện nay cũng là yếu tố quyết định cho việc mở rộng nguồn nhân lực nông nghiệp công nghệ cao vừa qua song còn mang nặng tính tự phát, manh mún và thiếu tính đột phá [5].

\subsubsection{Hạn chế trong phát triển chất lượng nguồn nhân lực dân tộc thiểu số}

Dù đã đạt được một số thành tựu nhưng chất lượng nguồn nhân lực vùng DTTS và miền núi vẫn còn nhiều hạn chế, đặt ra nhiều thách thức. Đó là trình độ học vấn và tỷ lệ được đào tạo của người lớn trong độ tuổi lao động.

Bảng 2. Trình độ học vấn và đào tạo nghề của người lớn DTTS (\% số người từ 16 tuổi trở lên) [9]

\begin{tabular}{lllllll}
\hline & $\begin{array}{l}\text { Không biết } \\
\text { chữ }\end{array}$ & Tiểu học & $\begin{array}{l}\text { Trung học } \\
\text { cơ sở }\end{array}$ & $\begin{array}{l}\text { Phổ thông } \\
\text { trung học }\end{array}$ & $\begin{array}{l}\text { Trên phổ } \\
\text { thông }\end{array}$ & $\begin{array}{l}\text { Qua ít nhất 1 } \\
\text { lớp đào tạo nghề }\end{array}$ \\
\hline TỐNG MẪU & 21,2 & 21,5 & $\mathbf{3 2 , 3}$ & 19,5 & 5,5 & $\mathbf{1 1 , 0}$ \\
DTTS tại chỗ & 24,4 & 23,5 & $\mathbf{3 0 , 5}$ & 16,8 & 4,8 & $\mathbf{6 , 9}$ \\
Chu-ru & 23,4 & 20,6 & $\mathbf{3 0 , 9}$ & 21,2 & 3,8 & $\mathbf{4 , 5}$ \\
Chil & 13,6 & 26,0 & $\mathbf{3 2 , 8}$ & 20,9 & 6,6 & $\mathbf{3 , 8}$ \\
Cơ-ho & 37,5 & 21,6 & $\mathbf{2 6 , 4}$ & 7,8 & 6,7 & $\mathbf{8 , 0}$ \\
Mạ & 29,8 & 26,6 & $\mathbf{2 9 , 8}$ & 10,9 & 2,9 & $\mathbf{1 3 , 7}$ \\
DTTS Di cư & 15,7 & 18,9 & $\mathbf{4 2 , 7}$ & 19,5 & 3,2 & $\mathbf{1 8 , 5}$ \\
Kinh & 3,3 & 11,9 & $\mathbf{3 8 , 3}$ & 37,2 & 9,3 & $\mathbf{2 5 , 7}$ \\
\hline
\end{tabular}

Bảng số liệu trên cho thấy hai vấn đề nổi cộm của về chất lượng nguồn nhân lực dân tộc thiểu số ở Lâm Đồng đó là (1) tỷ lệ người lao động qua đào tạo khá thấp, trung bình chỉ chiếm $11 \%$ đã qua ít nhất 1 lớp đào tạo. Trong đó tỷ lệ nhóm dân tộc thiểu số tại chổ qua đào tạo nghề thấp hơn rất nhiều (chỉ chiếm 6,9\%) so với nhóm dân tộc thiểu số di cư $(18,5 \%)$. Có những nhóm dân tộc thiểu số tại chỗ chỉ có $3,8 \%$ tỷ lệ đã qua ít nhất một lớp đào tạo. Đó còn chưa kể tới cùng với việc thiếu vốn, thiếu đất sản xuất sẽ ảnh hưởng đến hiệu suất và năng suất lao động của nhóm dân tộc thiểu số ở Lâm Đồng hiện nay. Vấn đề thứ hai, đó là (2) trình độ học vấn của nhóm trong độ tuổi lao động (từ 16 tuổi trở lên) tập trung từ trung học phổ thông trở xuống, tỷ lệ này cũng chỉ dao động từ $26-$ $38 \%$, trong khi ở những mức học cao hơn (từ trung học phổ thông trở lên), tỷ lệ này lại càng giảm (chỉ dao động từ 3,8-7\%). Điều này đặt ra bài toán về nâng cao trình độ học vấn cho nhóm dân tộc thiểu số ở Lâm Đồng hiện nay.

\section{Những định hướng giải pháp phát triển chất lượng nguồn nhân lực ở Lâm Đồng}

Mặc dù được đánh giá là một tỉnh có nhiều điều kiện thuận lợi về tự nhiên, môi trường, khí hậu, song trong tương quan với nhiều tỉnh thành khác, Lâm Đồng vẫn chưa phát huy được tiềm năng để tạo ra lợi thế cạnh tranh cho mình. Giải pháp cốt lõi cấp bách hiện nay đó là cần hướng đến phát triển chất lượng nguồn nhân lực cho tỉnh khi tập trung vào ba mũi nhọn cũng là ba thế mạnh của tỉnh đó là: phát triển nông nghiệp công nghệ cao, phát triển du lịch dịch vụ và nhân lực dân tộc thiểu số sẽ trở thành lợi thế cạnh tranh nếu có chiến lược phát triển đúng trọng tâm và hợp lý.

\subsection{Chiến luợc phát triển chất luợng nguồn nhân lưc nông nghiệp công nghệ cao}

Lâm Đồng đang thiếu và yếu về nhân sự về các lĩnh vực công nghệ sinh học, công nghệ nano, công nghệ thông tin quản trị tài chính 
thông minh, công nghệ đồng bộ năng lượng tái tạo, công nghệ rô bốt,... Do vậy, cần cử nhân sự chủ chốt trong lĩnh vực này đi đào tạo trong nước hoặc nước ngoài về các lĩnh vực chuyên sâu này.

Nông dân là một đội ngũ trực tiếp tham gia vào sản xuất, nên đội ngũ này cần được đào tạo, tập huấn chuyên môn sâu hơn nữa trong thời gian tới. Nếu điều kiện về nguồn lực kinh tế của tỉnh hạn chế, giải pháp đào tạo đội ngũ nông dân nòng cốt, trọng điểm làm "điểm sáng" để nhân rộng và làm mạnh đội ngũ này cho tỉnh. Đây cũng là một nhân tố tạo lợi thế cạnh tranh không chỉ đối với lĩnh vực nông nghiệp của tỉnh mà đóng góp cho việc phát triển kinh tế của tỉnh nói chung.

\subsection{Chiến lược nâng cao chất luợng nguồn nhân lục làm du lịch}

Để khắc phục và kiểm soát việc "nhà nhà làm du lịch, người người làm du lịch" và nâng cao tính chuyên nghiệp của nhân lực làm du lịch, thiết nghĩ, hai giải pháp then chốt cần hướng đến là khâu quản lý nhà nước và chế tài xử phạt đối với hoạt động dịch vụ du lịch (dịch vụ lưu trú, dịch vụ ăn uống, bán hàng, dịch vụ vui chơi, tour,... ) cần chặt chẽ và quyết liệt hơn nữa để đủ sức răn đe và chấn chỉnh hoạt động du lịch kém chất lượng. Cần hướng đến việc xây dựng thương hiệu, xây dựng hình ảnh cho du lịch Lâm Đồng, trong đó có xây dựng thương hiệu, hình ảnh cho cho các thành phố trung tâm để vừa chuẩn hóa về đội ngũ, vừa quản bá du lịch của địa phương.

Thứ hai, để nâng cao tính chuyên nghiệp của nhân lực phục vụ du lịch, ngoài các lớp đào tạo chuyên sâu về nghiệp vụ, kỹ năng nghề nghiệp, cần hướng đến giải pháp về tiền lương, chế độ đãi ngộ sẽ là những động lực và đòn bẩy thúc đẩy tăng tính chuyên nghiệp cho chất lượng độ ngũ nhân lực làm du lịch.

\subsection{Chiến lược phát triển chất lương nguồn nhân lục thiểu số ở lâm đồng}

Thứ nhất, để nâng cao năng lực đội ngũ CBCC người DTTS phải gắn với đường lối chính trị, trước hết là quán triệt chính sách dân tộc của Đảng, của chính quyền địa phương. Đào tạo đội ngũ $\mathrm{CBCC}$ người DTTS chính là tạo điều kiện để các DTTS vượt lên thực hiện quyền bình đẳng về chính trị, kinh tế, văn hóa giữa các dân tộc.

Thứ hai, đào tạo đội ngũ cán bộ dân tộc phải xuất phát từ yêu cầu phát triển kinh tế, khai thác thế mạnh về tài nguyên của vùng dân tộc và miền núi, đặc biệt là yêu cầu phát triển kinh tế - xã hội ở vùng DTTS, tạo điều kiện cho các dân tộc hòa nhập vào sự phát triển chung của cả nước. Cần có phong trào "đưa người dân DTTS, đưa phụ nữ DTTS ra khỏi làng" để vừa đi đào tạo vừa đi học tập kinh nghiệm các cộng đồng khác nhằm thúc đẩy tính tự tin, mạnh dạn trong sản xuất và đời sống.

Thứ ba, để phát triển chất lượng nhân lực dân tộc thiểu số mang tính bền vững, cần tính toán đầy đủ đến các đặc thù dân tộc và miền núi để có nội dung, chương trình và phương pháp đào tạo cũng như đầu tư ngân sách cho phù hợp. Tránh những chương trình, chính sách chung mà không có chính sách, chương trình riêng, đặc thù cho từng nhóm đối tượng, từng nhóm dân tộc thiểu số.

Thứ tư, phát triển chất lượng nhân lực DTTS phải gắn đào tạo, bồi dưỡng với sử dụng; phải có chính sách sử dụng tốt cán bộ dân tộc và có chế độ đãi ngộ thích đáng.

\section{Kết luận}

Tận dụng được những lợi thế của địa phương, Lâm Đồng trong những năm qua đã có những bước tiến đột phá trong chiến lược phát triển chất lượng nguồn nhân lực của địa phương. Không chỉ chuẩn hóa đội ngũ về cơ cấu, về số lượng mà còn về chất lượng ở cơ quan ban ngành cũng như trong nhiều lĩnh vực then chốt. Có thể nói, chất lượng nguồn nhân lực đã đóng góp đáng kể, có ý nghĩa vào sự phát triển các ngành kinh tế trọng điểm của địa phương là nông nghiệp và du lịch. Bên cạnh những thành tựu đáng kể đã đạt được, vẫn còn rất nhiều hạn chế trong đào tạo, phát triển 
nguồn nhân lực hiện nay của tỉnh. Tuy chất lượng nguồn nhân lực được nâng lên nhưng vẫn chưa đáp ứng được yêu cầu phát triển của địa phương, nhiều lĩnh vực thiếu cán bộ có trình độ chuyên môn, quản lý giỏi và đội ngũ cán bộ khoa học - kỹ thuật cùng công nhân lành nghề. Cùng với đó, kế hoạch đào tạo bồi dưỡng chưa sát với yêu cầu thực tiễn, hiệu quả của việc liên kết với một số cơ sở đào tạo cần được xem lại, gây lãng phí ngân sách nhà nước.

Chính vì vậy, Lâm Đồng trong thời gian đến cần đưa ra chiến lược phát triển dài hạn và trọng điểm trong kế hoạch của mình, đặc biệt là chiến lược về phát triển nguồn nhân lực chất lượng cao của tỉnh. Lâm Đồng không thể tạo ra lợi thế cạnh tranh về nguồn nhân lực nói chung so với các địa phương khác, nhưng việc tạo ra lợi thế cạnh tranh về các ngành, lĩnh vực trọng điểm thì hoàn toàn có thể. Mà để làm được điều này, cần có đội ngũ nhân lực chuyên gia về các lĩnh vực này mạnh về chất lượng, vững về đội ngũ. Đẩy mạnh nguồn nhân lực dân tộc thiểu số có chất lượng cũng là cách để đạt được mục đó dễ dàng hơn. Lâm Đồng cần ưu tiên phát triển nguồn nhân lực đủ về số lượng, cơ cấu hợp lý, nâng cao chất lượng, đáp ứng yêu cầu tái cơ cấu kinh tế, trọng tâm là tái cơ cấu nông nghiệp, phát triển mạnh dịch vụ du lịch, phát triển có chọn lọc một số ngành, đẩy mạnh công nghiệp hóa, hiện đại hóa và hội nhập quốc tế; đảm bảo quốc phòng và an ninh, xây dựng hệ thống chính trị vững mạnh.

\section{Tài liệu tham khảo}

[1] Lam Dong Statistical Yearbook (In Vietnamese), Lam Dong Statistical Office, 2017, p. 97.

[2] Nghiem Thi Thuy, Developing human resources to effectively exploit the advantages of Lam Dong province in the direction of sustainable development (In Vietnamese), Vu Thi Thuy Dung
(Editor) in Sociological Studies on the Central Highlands, Hanoi National University Press, 2018, p. 89.

[3] Dantocmiennui, Need sufficient human resources for quality and tourism development in Lam Dong - Central Highlands (In Vietnamese), 2015.

[4] https://www.dantocmiennui.vn/xa-hoi/can-nguonnhan-luc-du-ve-chat-va-luong-cho-du-lich-lamdong-\%E2\%80\%93-tay-nguyen-phattrien/377.html; (Accessed January 16, 2015).

[5] Baolamdong.vn, Developing hi-tech agricultural human resources in Lam Dong (In Vietnamese),

[6] http://baolamdong.vn/xahoi/201311/phat-triennguon-nhan-luc-nong-nghiep-cong-nghe-cao-olam-dong-2288813/2013. (Accessed November 24, 2013).

[7] Baolamdong.vn, Issues on developing high-tech agricultural human resources in Lam Dong (In Vietnamese), 2015.

[8] http://www.baolamdong.vn/upload/others/201507/ 14103_so_ngay_17.7.2015.pdf (Accessed July 17, 2015).

[9] Nguyen Thi Bich Thu, Assessing the situation and proposing solutions to develop ethnic minority human resources in Lam Dong province in the period of 2017 - 2025, orientation to 2030. Lam Dong Department of Science and Technology (In Vietnamese), 2018.

[10] Report to Department of Home Affairs of Lam Dong. No. 1/BC-SNV (In Vietnamese), January 2015.

[11] Nguyen Duc Vinh, Dang Nguyen Anh, Nghiem Thi Thuy, Population and human resource changes in sustainable development in the Central Highlands (In Vietnamese), printed in the book "Sociology Studies on the Central Highlands" $\mathrm{Vu}$ Thi Thuy Dung (Editor), Hanoi National University Press, 2018, pp. 88 - 97.

[12] Nguyen Tuan Anh, Current situation, solutions for sustainable poverty reduction according to multidimensional poverty standards for ethnic minorities in Lam Dong province in the period of 2016-2020 (In Vietnamese), Lam Dong Department of Science and Technology, 2018. 